\title{
The impact of oceanic circulation and phase transfer on the dispersion of radionuclides released from the Fukushima Dai-ichi Nuclear Power Plant
}

\author{
Y. Choi, S. Kida, and K. Takahashi \\ Earth Simulator Center, Japan Agency for Marine-Earth Science and Technology, 3173-25 Showa-machi, Kanazawa-ku, \\ Yokohama Kanagawa 236-0001, Japan \\ Correspondence to: S. Kida (kidas@jamstec.go.jp)
}

Received: 30 December 2012 - Published in Biogeosciences Discuss.: 27 February 2013

Revised: 23 May 2013 - Accepted: 5 June 2013 - Published: 22 July 2013

\begin{abstract}
The mechanism behind the dispersion of radionuclides released from the Fukushima Dai-ichi Nuclear Power Plant on March 2011 is investigated using a numerical model. This model is a Lagrangian particle tracking-ocean circulation coupled model that is capable of solving the movement and migration of radionuclides between seawater, particulates, and bottom sediments. Model simulations show the radionuclides dispersing rapidly into the interior of the North Pacific once they enter a meso-scale eddy. However, some radionuclides also remain near the coast, with spatial distribution depending strongly on the oceanic circulation during the first month after the release. Major adsorption to bottom sediments occurs during this first month and many of these radionuclides remain on the sea floor once they are adsorbed. Model results suggest that weak offshore advection during the first month will increase the adsorption of radionuclides to bottom sediments and decelerate the dispersion to the open ocean. If vertical mixing is weak, however, fewer radionuclides reach the sea floor and adsorb to bottom sediments. More radionuclides will then quickly disperse to the open ocean.
\end{abstract}

\section{The release of radionuclides from the coast of Fukushima}

On March 2011, a significant amount of radionuclides was released to the ocean from the Fukushima Dai-ichi Nuclear Power Plant (hereafter FNPP) (Fig. 1). The amount of ${ }^{137} \mathrm{Cs}$ released is estimated to be about $3-27 \mathrm{PBq}$ based on numer- ical models and observations (Kawamura et al., 2011; Bailly du Bois et al., 2011; Tsumune et al., 2012; Masumoto et al. 2012; Miyazawa et al., 2012; Estournel et al., 2012), which is comparable to the amount that was released to the atmosphere (about 15 PBq, NERH, 2011). Recent studies, based on more rigorous calculation methods, tend to show an estimate around 5-6 PBq. Fukushima-originated radionuclides were also observed in the Kuroshio Extension region of the North Pacific in June 2011 (Buesseler et al., 2012). Observations show that radionuclides quickly dispersed to the open ocean within a few months after their release from the coast. At the same time, however, observations show high levels of radionuclides remaining in seawater and sediments near the coast (MEXT, 2011). These observations indicate that some radionuclides do not quickly disperse to the open ocean but stay near the coast (Fig. 2).

What are the processes that control the dispersion of radionuclides near the Fukushima coast? Numerical models have been used to understand how the dispersion of radionuclides occurred in more detail, from local to the basin scale. Tsumune et al. (2012) used a coastal model and an Eulerian passive tracer model and showed that the radionuclides likely dispersed from the Sendai Bay to the coast of Ibaraki and towards the open ocean as far east as $100 \mathrm{~km}$ from the FNPP (Fig. 1). Miyazawa et al. (2012) used a nested high-resolution regional ocean model and an Eulerian passive tracer model to examine the impact of the wind, river outflow, and tides on the dispersion. They showed the radionuclides dispersing to the open ocean by April and suggested that oceanic circulation plays the dominant role. The wind is found to have a 


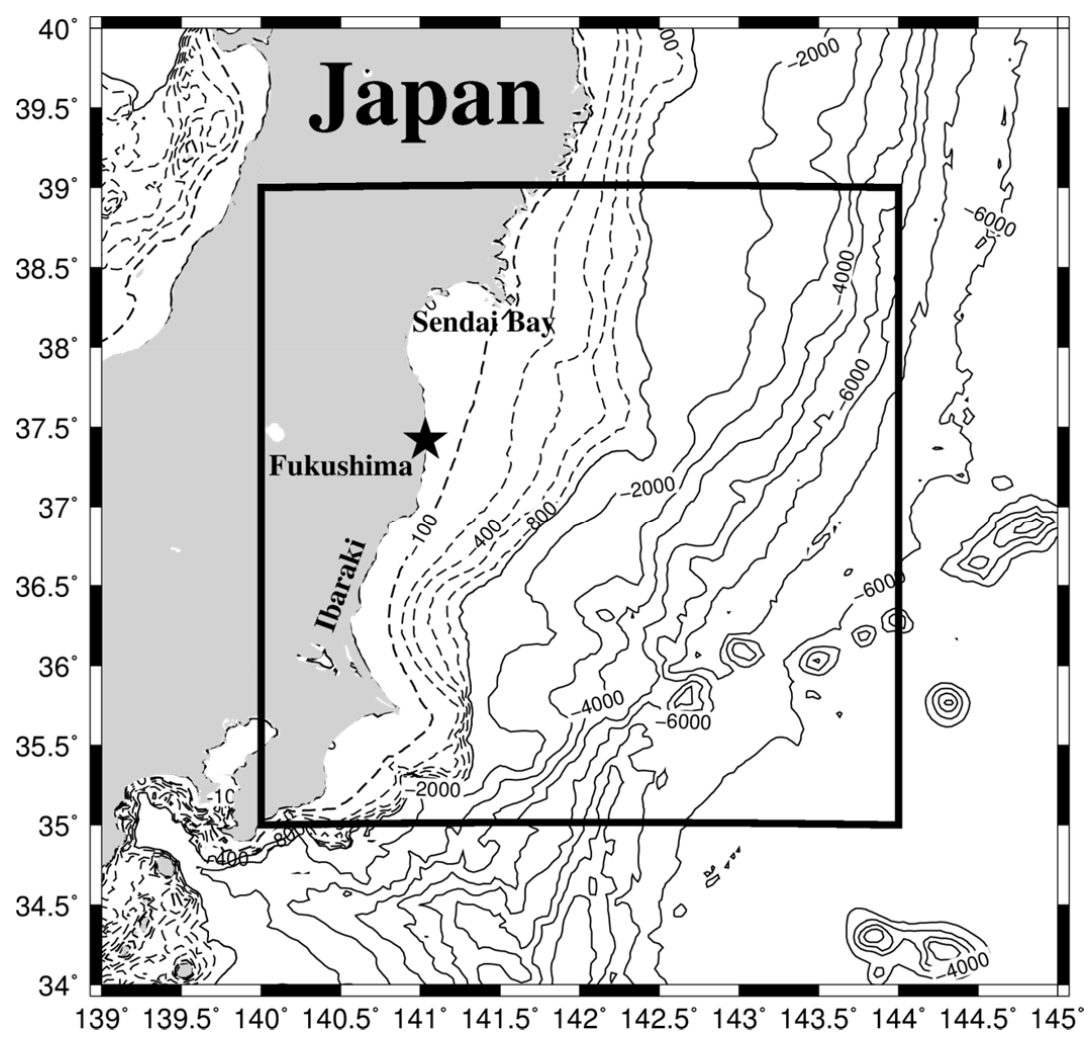

Fig. 1. Bottom topography of the region close to the FNPP. Contours are drawn for 100, 200, 400, 600, 800, $1000 \mathrm{~m}$, and every $1000 \mathrm{~m}$ after that. Black star indicates the location of the FNPP. Model domain is the squared region surrounded by the thick black solid line. The continental shelf break, which can be roughly interpreted from the $200 \mathrm{~m}$ contour line, is located close to the coast near Ibaraki but further off-shore near Fukushima.

strong influence on the dispersion near the coast. Honda et al. (2012) used a Lagrangian particle-tracking model based on oceanic surface currents and showed that radionuclides are capable of travelling as far east as $155^{\circ} \mathrm{E}$ in a month or so.

While several studies have investigated the mechanism behind the dispersion of radionuclides near the Fukushima coast, studies incorporating the migration of radionuclides between seawater, particulate matter, and bottom sediments have been limited. Periàñez et al. (2012) recently suggested that significant adsorption to bottom sediments likely occurred near the FNPP. However, the spatial resolution and the coupling timescale with the oceanic model were moderate and thus the role of detailed flow field remains an open question. Migration of radionuclides into different phases is a major process that could decide how much and where the radionuclides remain trapped near the coast. The radionuclides dissolved in seawater or adsorbed in particulate matter will likely disperse to the open ocean along with the seawater, whereas the radionuclides adsorbed in bottom sediments will likely remain on the sea floor near the coast for some time. Since many biological activities take place along the coast, understanding the dispersion of radionuclides there is impor- tant and observations do show quite a large amount of radionuclides remaining near the FNPP even after few months after its release (Fig. 2). This motivates us to examine how phase transfer of radionuclides may have played a role on the dispersion of radionuclides.

In this paper, we will investigate the processes responsible for the dispersion of radionuclides near the Fukushima coast using a Lagrangian particle-tracking model, which is coupled to a high-resolution ocean circulation model. The particle-tracking model is capable of solving the migration of radionuclides between three phases; dissolved phase, particulate phase, and bottom sediment phase, which is the main focus of this study. By coupling the particle-tracking model to a high-resolution ocean numerical model, we anticipate that the turbulent flow field of the region is realistically resolved as well. The details of the model setup will be described next in Sect. 2. The simulation results are then presented and compared with observations in Sect. 3. The sensitivity of the dispersion to the magnitude of vertical mixing is examined in Sect. 4. Summary and discussion are presented in Sect. 5. 

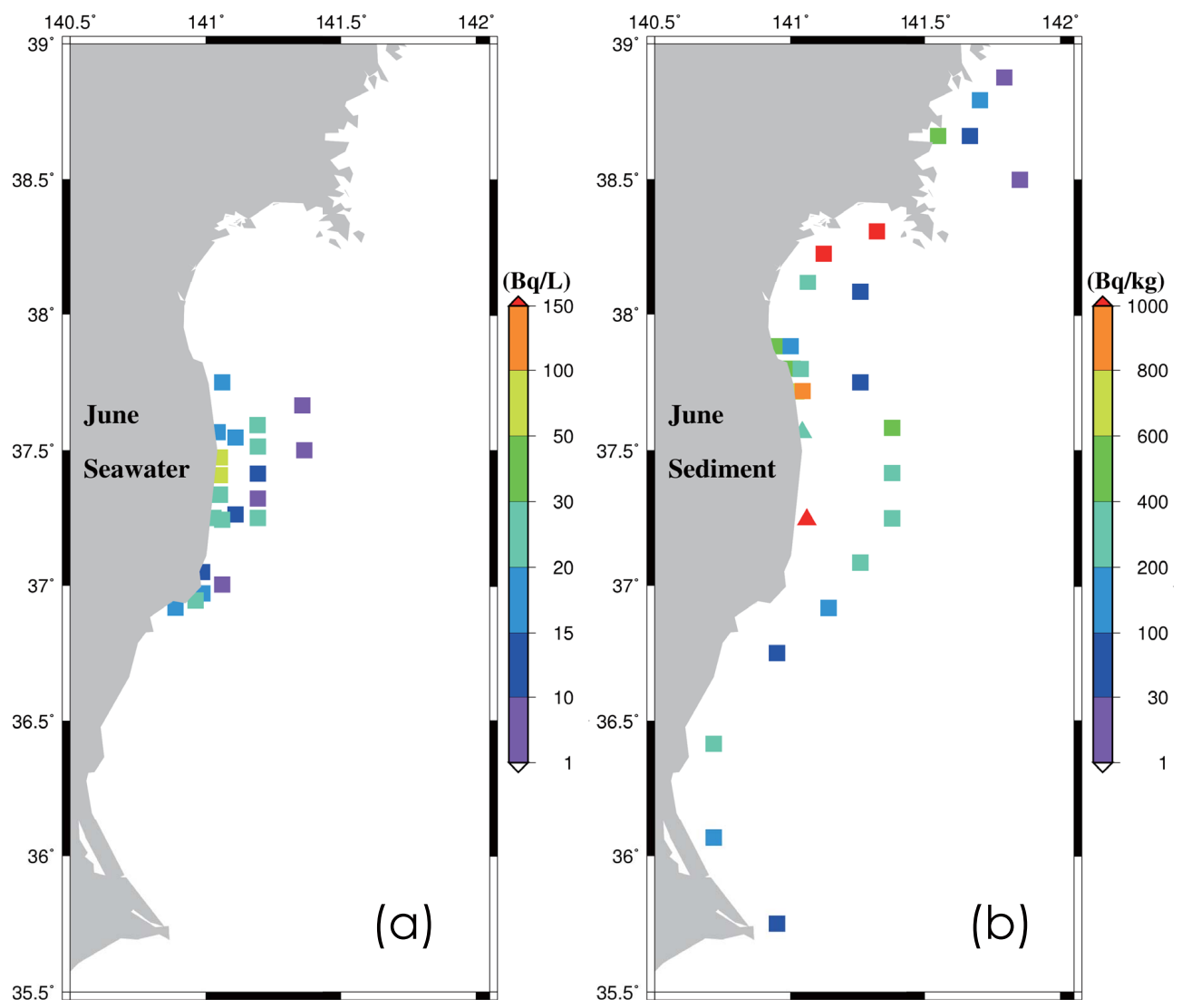

Fig. 2. Concentrations of radionuclides in (a) seawater $\left[\mathrm{Bq} \mathrm{L}^{-1}\right]$ and (b) bottom sediments $\left[\mathrm{Bq} \mathrm{kg}^{-1}\right.$ dry] observed in June, 2011 (MEXT, 2011). Samplings of seawater were taken from surface to $150 \mathrm{~m}$ depth. Note that data from TEPCO are measured in $\left[\mathrm{Bq} \mathrm{kg}^{-1}\right.$ wet] and are shown in triangles. The values are also converted to [ $\left.\mathrm{Bq} \mathrm{kg}^{-1} \mathrm{dry}\right]$ by multiplying by 0.75 (MEXT, 2011). Higher levels of radionuclides are observed near the FNPP and also along the coast from the southern tip of Ibaraki to the Sendai Bay.

\section{Description of the particle tracking-ocean circulation coupled model}

A regional numerical ocean circulation model is used to simulate the flow field near the coast of Fukushima from 1 December 2010 to 30 June 2011. A Lagrangian particletracking model will then use this flow field to solve the movement of radionuclides from the FNPP as it migrates into different phases. The coupling between the two models occurs every $30 \mathrm{~min}$.

\subsection{The ocean circulation model}

The oceanic component of the Multi-Scale Simulator for the Geo-environment (MSSG) is used for the ocean circulation model (Kida, 2011). This model is a $\mathrm{z}$-coordinate model with a non-hydrostatic capability but we will use the hydrostatic option here. The model domain covers from 140.2 to $143.2^{\circ} \mathrm{E}$ in longitude and from 34.85 to $39.14^{\circ} \mathrm{N}$ in latitude. A fine-resolution horizontal grid of about $2 \mathrm{~km}$ (Fig. 3) is used in order to resolve the eddy-rich flow field, which is an essential part of the dynamics in the region. The coast of
Fukushima is located in the Kuroshio-Oyashio Interfrontal Zone (Yasuda, 2003) where two western boundary currents collide and intense meso-scale eddies are generated. Bottom depths $(D)$ are a spatial average of ETOPO1 (Amante and Eakins, 2009) with 73 levels in the vertical ranging from $3 \mathrm{~m}$ resolution near the surface to $250 \mathrm{~m}$ near the bottom.

The lateral boundaries of the flow field, temperature, and salinity are set to the daily outputs of the Japan Coastal Ocean Predictability Experiment (JCOPE)-2, a dataassimilated product of the region with a resolution of $1 / 12^{\circ}$ (Miyazawa et al., 2009). JCOPE2 is known to assimilate the pathway of the Kuroshio well and we thus believe that its outputs are reasonably close to reality. There is a sponge layer of about $40 \mathrm{~km}$ around the lateral boundaries so that the simulated flow field is smoothly adjusted to that of JCOPE2 output. Surface temperature and salinity are also restored to that of JCOPE2 outputs with a restoring timescale of 1 day. While we understand that this is a rather strong restoring timescale, we chose to match it with that of the JCOPE2 output frequency. 
(a)

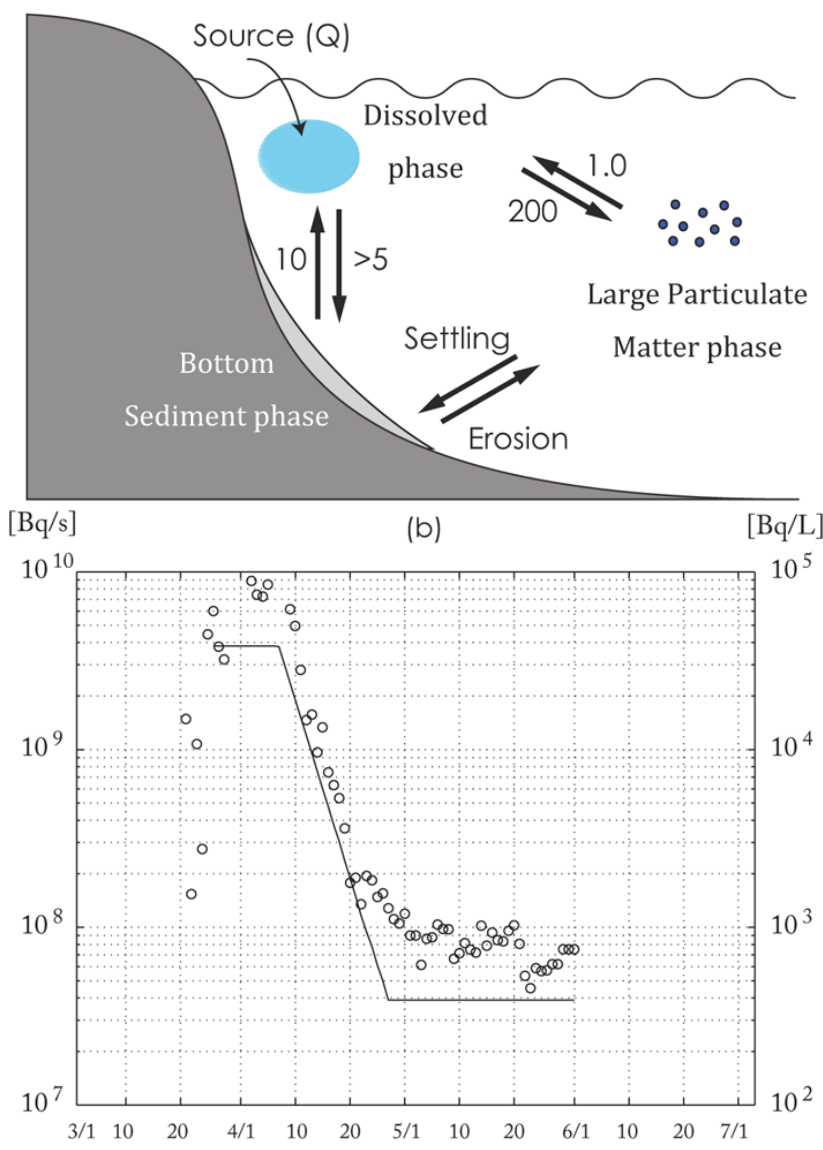

Fig. 3. (a) A schematic showing the three phases solved by the particle-tracking model along with the timescale of the phase transfer in [days]. Radionuclides are first introduced in dissolved phase. (b) Time series of the ${ }^{137} \mathrm{Cs}$ source term based on Tsumune et al. (2012) are shown in a black solid line ([Bq s$\left.{ }^{-1}\right]$, left axis). Observed concentrations at the outlet of Dai-ichi FNPP (TEPCO, 2011) are shown in a black circles ([Bq $\left.\mathrm{L}^{-1}\right]$, right axis).

Surface wind stress is based on $10 \mathrm{~m}$ wind of the Grid Point Value of Meso-Scale Model (GPV/MSM) that is provided by the Japan Meteorological Agency. This product has outputs every $6 \mathrm{~h}$ and high horizontal resolution of about $0.05^{\circ}$. The formula of Large and Pond (1981) is used to estimate the wind stress from the wind. Smagorinsky-type Laplacian viscosity and diffusion is used for the subgrid scale parameterization in the lateral direction with a coefficient of 0.4 . Noh-Kim vertical mixing scheme is used for vertical viscosity and diffusion (Noh and Kim, 1999).

\subsection{Lagrangian particle-tracking model}

A Lagrangian particle-tracking model is used to solve the movement and the migration of radionuclides since such a coordinate system is natural to the movement of particles in the ocean. This model is originally developed to simulate the dispersion of spilled oil (Choi et al., 2011, 2012) and we have modified the equations so that they are appropriate for radionuclides. The dispersion and phase transfer of radionuclides are solved three-dimensionally based on the following equations:

$\frac{\mathrm{d} C_{\mathrm{diss}}}{\mathrm{d} t}=Q-k_{1} C_{\mathrm{diss}}+k_{2} C_{\mathrm{LPM}}-k_{3} C_{\mathrm{diss}}+\phi k_{2} C_{\mathrm{sed}}$,

$\frac{\mathrm{d} C_{\mathrm{LPM}}}{\mathrm{d} t}=+k_{1} C_{\mathrm{diss}}-k_{2} C_{\mathrm{LPM}}-\mathrm{Set}+$ Ero $\quad$ and

$\frac{\mathrm{d} C_{\text {sed }}}{\mathrm{d} t}=+k_{3} C_{\mathrm{diss}}-\phi k_{2} C_{\mathrm{sed}}+$ Set - Ero.

$C_{\mathrm{diss}}, C_{\mathrm{LPM}}$, and $C_{\mathrm{sed}}$ are the concentration of radionuclides that are dissolved in seawater, adsorbed in large particulate matter (LPM) (particulates with a diameter between 0.5 and $62.5 \mu \mathrm{m})$, and adsorbed in bottom sediments, respectively. We will refer to these three phases as radionuclides in dissolved phase, LPM phase, and bottom sediment phase, hereafter. $\mathrm{d} / \mathrm{d} t$ is the total derivative following the motion of the particle, $u$, and the impact of the oceanic flow and mixing is included in this term. $Q$ is the source term. Terms with $k_{n}$ are the phase transition terms. "Set" is the settling from LPM phase to bottom sediment phase and "Ero" is the erosion from bottom sediment phase to LPM phase. These two processes occur only at the sea floor. Equations (1-3) are roughly equivalent to that used in Periàñez and Elliott (2002) and the schematic of the processes involved are shown in Fig. 3a. Note that we have neglected the decaying process because the half-life of $30 \mathrm{yr}$ for ${ }^{137} \mathrm{Cs}$ is significantly longer than the model integration time pursued in this study.

Radionuclides in dissolved phase follow the oceanic flow field $\left(\boldsymbol{u}_{\mathrm{o}}\right)$ so its pathway is $\boldsymbol{u}=\left(u_{\mathrm{o}}, v_{\mathrm{o}}, w_{\mathrm{o}}\right)$. Radionuclides in LPM phase have an additional settling velocity $\left(w_{\mathrm{s}}\right)$ term so its pathway is $\boldsymbol{u}=\left(u_{\mathrm{o}}, v_{\mathrm{o}}, w_{\mathrm{o}}+w_{\mathrm{s}}\right) . w_{\mathrm{s}}$ is set to $-2 \times 10^{-4} \mathrm{~m} \mathrm{~s}^{-1}$ assuming that the mean radius of LPM is about $15 \mu \mathrm{m}$. While the settling velocity of suspended particles is often expressed as a function of suspended matter concentration or diameter of particles (e.g. Mehta, 1989; Nicholson and O'Connor, 1986; Sternberg et al., 1999), we have chosen to use a single value following Kobayashi et al. (2007). Radionuclides in bottom sediment phase are not advected.

The oceanic flow and mixing will be represented by $\boldsymbol{u}_{\mathrm{o}}=$ $\boldsymbol{u}_{\mathrm{m}}+\boldsymbol{u}^{\prime}$, where $\boldsymbol{u}_{\mathrm{m}}$ is the flow simulated in the ocean model and $\boldsymbol{u}^{\prime}$ is the turbulent flow in the subgrid scale. $\boldsymbol{u}^{\prime}$ is added because the ocean circulation model does not explicitly solve the subgrid scale motion (mixing) and uses eddy diffusivity instead. Here, $\boldsymbol{u}^{\prime}$ will be represented in the form of a random walk following Periàñez and Elliott (2002):

$u^{\prime}=R \cos \vartheta \cdot \sqrt{\frac{12 A_{\mathrm{H}}}{\Delta t}}$, 
$v^{\prime}=R \cos \vartheta \cdot \sqrt{\frac{12 A_{\mathrm{H}}}{\Delta t}}$ and

$w^{\prime}=R \sqrt{\frac{2 A_{\mathrm{V}}}{\Delta t}}$.

$R$ is a random number between -1 and $1 . \theta$ is a random angle between 0 to $\pi$. The horizontal diffusivity coefficient, $A_{\mathrm{H}}$, and vertical diffusivity coefficient, $A_{\mathrm{z}}$, are set to those that are calculated in the ocean model.

The source term, $Q$, is prescribed based on the idealized discharge time series suggested by Tsumune (2012) (Fig. 3b). However, the total input is adjusted to $5.5 \mathrm{PBq}$ so that it is within the range estimated in recent studies (e.g. Masumoto et al., 2012). This idealized source term has a constant rate of $3.3 \mathrm{TBq}$ day $^{-1}$ from 26 March to 6 April but decreases exponentially to $0.033 \mathrm{TBq} \mathrm{day}^{-1}$ after 6 April and then remains constant up to 31 May. Source term is zero beyond 31 May. Radionuclides are added to a $1.0 \mathrm{~km}$ (meridional $) \times 500 \mathrm{~m}($ zonal $) \times 5 \mathrm{~m}($ from the surface $)$ boxed region next to the FNPP with each particle representing $10^{10} \mathrm{~Bq}$ of radionuclides. We did not include atmospheric fallouts because we wanted to focus on understanding the impact of phase transfer on the radionuclides that were directly released to the ocean.

Because the specific parameters appropriate for the region around the FNPP are unknown, the parameters and expressions for the phase transfer, settling, and erosion are basically based on past studies (Periàñez (2000), Periàñez and Elliott (2002), and Kobayashi et al. (2007), except for the LPM concentration as described below. There are obviously detailed differences in the parameters for every sea as well as spatial variability within. However, we consider the values reasonable for capturing and understanding the processes involved in the dispersion of radionuclides to its first order.

The phase transition terms are calculated based on a stochastic method: Radionuclides are transferred from one phase to another with a probability of $1-\exp ^{-k_{n} \Delta t}$. Terms with $k_{1}, k_{2}, k_{3}$, and $\phi k_{2}$ represent the adsorption from dissolved to LPM phase, desorption from LPM to dissolved phase, adsorption from dissolved to bottom sediment phase, and desorption from bottom sediment to dissolved phase, respectively. $k_{1}$ is set to about $(200 \text { day })^{-1}$ and is estimated assuming that the mean LPM concentration is $0.1 \mathrm{mg} \mathrm{L}^{-1}$. A constant value is used for its simplicity. Because the concentration value is unclear for the oceanic region surrounding the FNPP, we decided to use a value based on studies in the North Sea. This sea is shallower and has larger freshwater input but is an open sea like Fukushima and has similar magnitude of tidal currents. Van Raaphorst et al. (1998) show the suspended particulate matter concentration in the oceanic region of the North Sea to be about one order smaller than that in the English Channel or the narrow and shallow regions near the coast with large freshwater input. We therefore chose a value that is about one order less than the English Channel, where concentration on the order of $O(1)-O(10)$ is observed ( 1 to $6 \mathrm{mg} \mathrm{L}^{-1}$ also by Lafite et al., $2000 ; 3.4 \mathrm{mg} \mathrm{L}^{-1}$ by van Alphen, 1990). $k_{2}$ is set to $(1.0 \text { day })^{-1}$. Adsorption from dissolved to bottom sediment phase occurs when radionuclides reach the bottom. $k_{3}$ is expressed as an inverse function of depth $\left(=4.2 \times 10^{-5} / D[\mathrm{~s}]\right)$ so its magnitude would be about $(5 \text { days })^{-1}$ at $20 \mathrm{~m}$ depth, but more than $(30 \text { days })^{-1}$ where deeper than $100 \mathrm{~m}$. The correction parameter $\phi$, which represents that not all the sediment particles are in contact with water, is set to 0.1 . Settling occurs once the radionuclides in LPM phase land on the sea floor. Erosion occurs as the bottom flow speed increases $\left(=2.4 \times 10^{-4}|u|^{3.4}\right)$.

The numerical experiments based on the setup as described above will be referred to as CTRL hereafter. To test the sensitivity of the dispersion to the magnitude of vertical mixing, we have further pursued an experiment where the vertical mixing coefficient used in Eq. (6) is an order smaller value from that used in CTRL. The magnitude of the vertical mixing coefficient can vary significantly due to the actual weather, seasons, and biological conditions and thus we would like to learn how sensitive the simulation results are to such factors. This experiment will be referred to as SMIX hereafter. As we will show later on, the magnitude of vertical mixing has a strong impact on the adsorption of radionuclides to bottom sediments as well as the rapidness of their dispersion to the open ocean.

\subsection{Observational products}

Model simulations are compared with the monthly averages of in situ observations for radionuclides in seawater and bottom sediments near the Fukushima coast. Observed data are provided by TEPCO, the Ministry of Education, Culture, Sports, Science and Technology (MEXT), the Ministry of the Environment (ME), and Fukushima Prefecture (FP) through the MEXT website (http://radioactivity.mext.go.jp) (MEXT, 2011). Concentration of radionuclides in bottom sediments shown in Fig. 2 are drawn from this data set and most of the observations are near the coast of the FNPP. Observations by TEPCO are measured by $\left[\mathrm{Bq} \mathrm{kg}^{-1}\right.$ wet] while others are $\left[\mathrm{Bq} \mathrm{kg}^{-1}\right.$ dry]. Data provided by TEPCO are therefore shown in triangles to clarify this difference. The values are also converted to [ $\mathrm{Bq} \mathrm{kg}^{-1}$ dry] by multiplying 0.75 , which is the average dry/wet ratio observed near the coast of Fukushima (MEXT, 2011). Such ratio obviously differs for each location but our aim is to get the first-order picture on the magnitude and the spatial variability of radionuclides adsorbed to bottom sediments. Satellite imageries of surface temperature by the Moderate-Resolution Imaging Spectroradiometer (MODIS) are also used for evaluating the spatial structure of the flow field in the region. This product has a spatial resolution of $4 \mathrm{~km}$ and has better spatial resolution than the sea surface height from AVISO. Although MODIS 
data is sometimes contaminated by the clouds, it shows good spatial coverage roughly every week.

\section{The simulated oceanic flow field and the dispersion of radionuclides}

We will first describe the surface flow field simulated in CTRL. The dispersion of radionuclides will be described next. What we find is that in the presence of migration between dissolved phase, LPM phase, and bottom sediment phase, a significant amount of radionuclides remains close to the coast even after few months after its release.

\subsection{The oceanic flow field}

The flow field near the Fukushima coast shows a weak northeastward flow from March to April roughly along the $100 \mathrm{~m}$ bathymetric contour line (Fig. 4a-c). This northward flow appears to strengthen gradually in April, bring warm SST water from the south, and create a SST front west and east side of this flow. Such SST fronts are found in observations as well (Fig. 5a-c). While the weekly averaged flow field shows a general northeastward flow near the coast, it is associated with significant variability and a southward flow is occasionally found along the coast of FNPP in late March (Fig. 4a). This southward flow advects cold SST water from the northern Sendai Bay and creates a SST front near the coast. The flow field much offshore of Fukushima shows a southeastward flow from March to April but the flow field in this region is also highly variable and is associated with many meso-scale eddies.

The flow field near the Ibaraki coast shows the presence of an anti-cyclonic eddy from March to April (Fig. 4a-c). This eddy is centered around $36.2^{\circ} \mathrm{N}$ and $141.4^{\circ} \mathrm{E}$ with a size of about $100 \mathrm{~km}$. The presence of such an eddy, which is associated with a warmer SST than that near the coast, is also observed although its signal is slightly weaker (Fig. 5a-c). The anti-cyclonic eddy begins to merge with the Kuroshio Extension in late April (Fig. 4c) and then completely merge by mid-May (Fig. 4d). It reestablishes again in late May when the Kuroshio Extension shifts south. This anti-cyclonic eddy in June is centered around $36.6^{\circ} \mathrm{N}$ and $141.7^{\circ} \mathrm{E}$, which is slightly northward and eastward than that found in April.

When an extra-tropical cyclone passes over the region at the end of May, the flow along the coast of Fukushima and Ibaraki abruptly becomes a strong southward flow for a few days (Fig. 4e). A strong wind event forces an accumulation of water near the coast and induces a southward flow that becomes as fast as $1.8 \mathrm{~m} \mathrm{~s}^{-1}$. This flow advects cold SST water from the north and creates a cold SST region along the coast, which is found in observations as well (Fig. 5e). The use of SST nudging, however, may have weakened its narrow and cold structure in the model (compared to observations) because the SST is nudged towards SST values that have lower spatial resolution than the model. The region warms up by late June and the SST front near the coast weakens (Figs. 4f and 5f).

\subsection{The dispersion of radionuclides}

Radionuclides in dissolved phase and LPM phase move roughly along with seawater so their spatial distribution will be described together. The behavior of these radionuclides is the one that can be compared with past studies where radionuclides are treated as a passive tracer and phase transfers do not occur.

\subsubsection{Radionuclides in seawater}

Soon after the major release of radionuclides, radionuclides in seawater (dissolved phase and LPM phase) are advected south for a few days. However, they are eventually advected north, following the average northward flow field from March to April (Fig. 6a and b) and establish a significant north-south asymmetry in its spatial distribution. Many of the radionuclides also spread inside the Sendai Bay (Fig. 6c), where the topography is shallow. The northerly wind from March to early April is likely behind such dispersion because a northerly wind forces a westward surface Ekman transport. This northerly wind weakens by late April and the radionuclides then appear to spread following the northward oceanic flow that exists along the bathymetric lines of about 100$200 \mathrm{~m}$. By the end of April, the wind turns south and the surface Ekman transport reverses towards the east. The radionuclides begin to spread to the open ocean as they move anticyclonically towards the Kuroshio Extension (Fig. 6d).

The meridional asymmetry weakens abruptly at the end of May when an extra-tropical cyclone crosses over Japan and induces a strong southward flow along the coast of Ibaraki (Fig. 6e). The strong southward flow brings a significant amount of radionuclides towards the south of the FNPP. However, the majority of these radionuclides appear not to reach the southern tip of Ibaraki where the radionuclides can enter the Kuroshio Extension and disperse to the North Pacific. Dispersion to the interior of the North Pacific is still found to occur mostly east of the FNPP, where an anticyclonic eddy advects the radionuclides southeast and toward the Kuroshio Extension region (Fig. 6d, e, and f).

\subsubsection{Radionuclides in bottom sediment phase}

We find the majority of the radionuclides adsorbed in bottom sediments where it is shallow $(<100 \mathrm{~m})$ (Fig. 7a-f). While the transfer rate from dissolved to LPM phase is small, the magnitude of the source is large and thus can create a decent amount of radionuclides in LPM phase. When these radionuclides in LPM phase reach the bottom, they will settle on the sea floor and transfer to bottom sediment phase. Note that in order to make the comparison between the model results and observations easier, model results are converted from 
(a) Mar 25-31

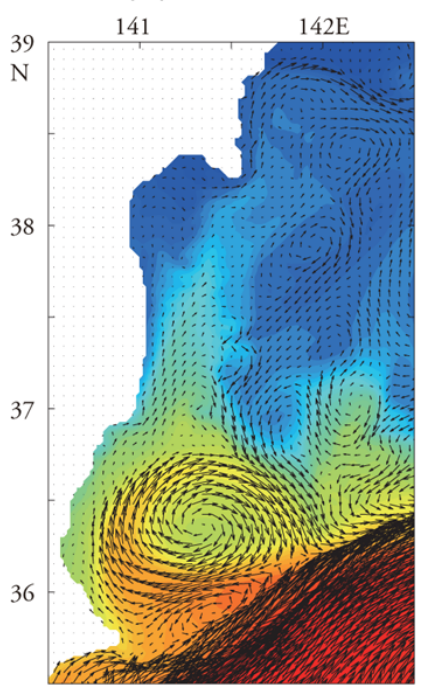

141

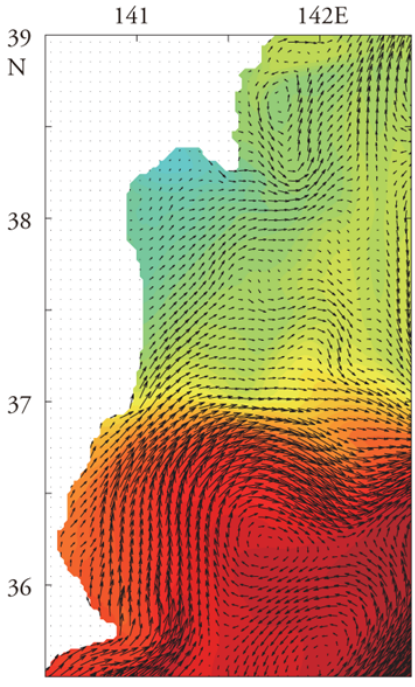

(d) May 14-20 (b) Apr 8-14

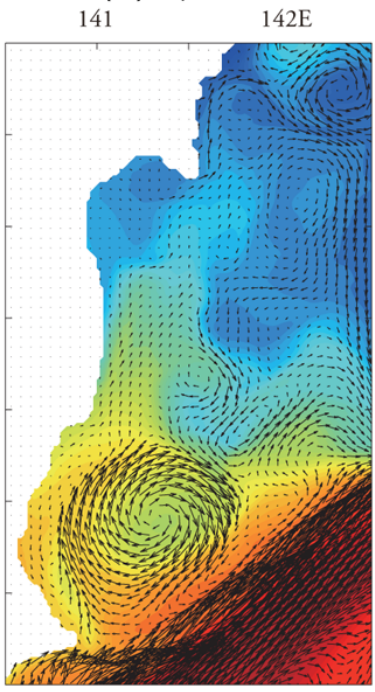

141

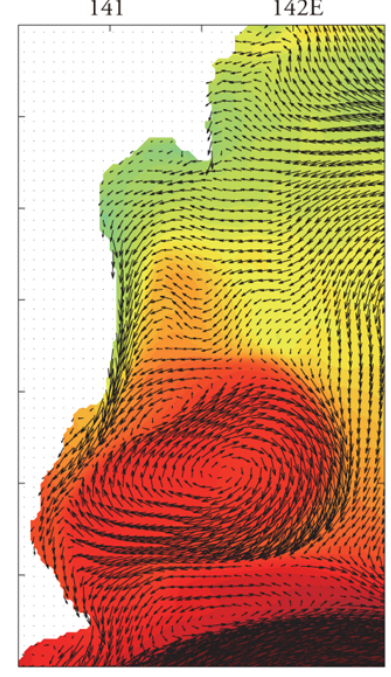

(e) May 29 - June 1 (c) Apr 23-29

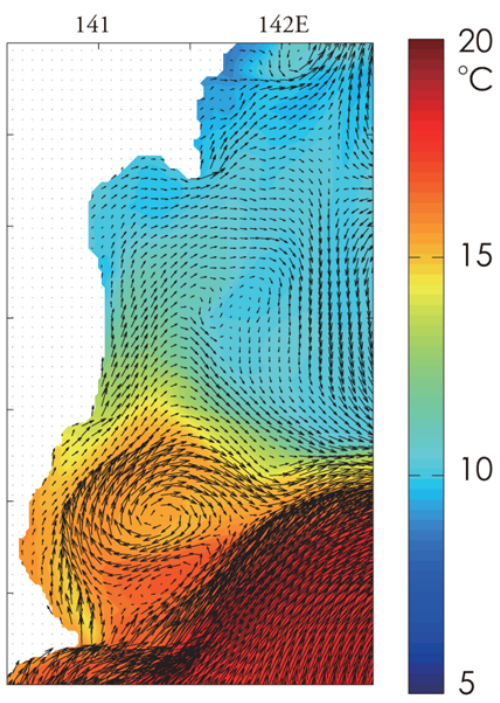

141

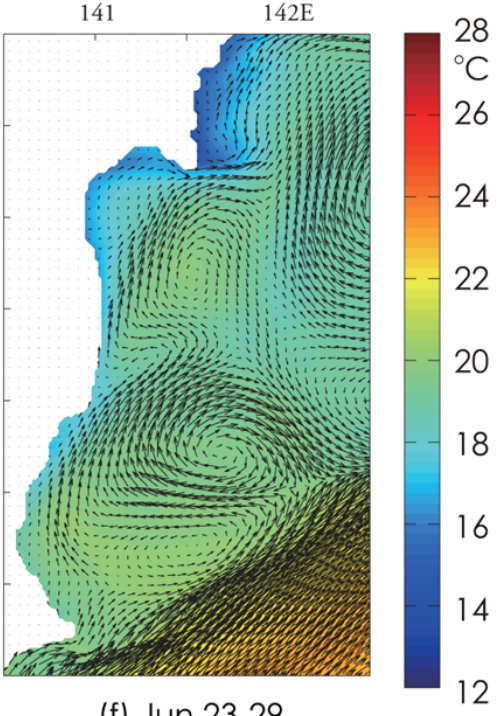

0

(f) Jun 23-29

Fig. 4. Simulated surface flow fields and the SST for CTRL. (a) 25-31 March, (b) 8-14 April, (c) 23-29 April, (d) 14-20 May, (e) 29 May1 June, and (f) 23-29 June 2011. Color contours are shown on the top right for (a-e) but bottom right for (f). The color contour is different for (f) so that it is similar to Fig. $5 \mathrm{f}$.

$\left[\mathrm{Bq} \mathrm{m}^{-2}\right]$ to $\left[\mathrm{Bq} \mathrm{kg}^{-1} \mathrm{dry}\right]$ in the figures. We have assumed that the bulk density of bottom sediments is $900 \mathrm{~kg} \mathrm{~m}^{-3}$ and that the radionuclides are trapped within the top $10 \mathrm{~cm}$ from the sea floor, thus $\left[\mathrm{Bq} \mathrm{kg}^{-1} \mathrm{dry}\right]=1 /(0.1 \times 900)\left[\mathrm{Bq} \mathrm{m}^{-2}\right]$.

Phase transfer from dissolved to bottom sediment phase or LPM to bottom sediment phase occur only at the bottom so the radionuclides that are released at the surface need some time to reach the bottom before they are adsorbed to bottom sediments. For a water column of about $50 \mathrm{~m}$ deep and with a vertical mixing coefficient of about $1 \times 10^{-2} \mathrm{~m}^{2} \mathrm{~s}^{-1}$, the radionuclides need only $2-3$ days to reach the bottom. So the adsorption to bottom sediments can occur rather quickly.
For a water column of more than $200 \mathrm{~m}$ deep, however, the radionuclides need more than a month to reach the bottom. This is assuming that the vertical mixing coefficient is as large as $1 \times 10^{-2} \mathrm{~m}^{2} \mathrm{~s}^{-1}$ from top to bottom. Since the surface mixed layer with a vertical mixing coefficient of the order $10^{-2} \mathrm{~m}^{2} \mathrm{~s}^{-1}$ is mostly limited to the top $100 \mathrm{~m}$, we consider it reasonable that not much adsorption to bottom sediments is found where the bottom is more than a few hundred meters deep. We find the changes in the magnitude of the settling velocity to increase the amount of radionuclides in bottom sediment phase but not to change their basic spatial distribution qualitatively. 
(a) $3 / 29$

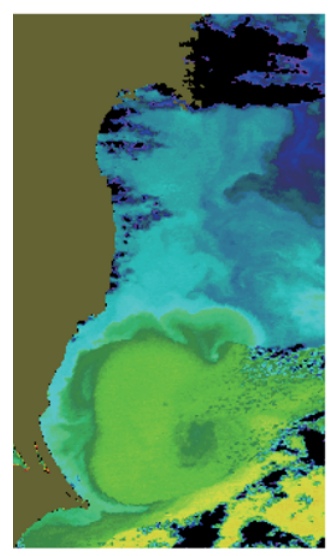

(d) $5 / 18$

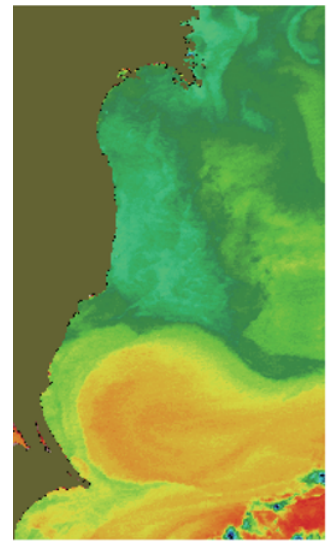

(b) $4 / 12$

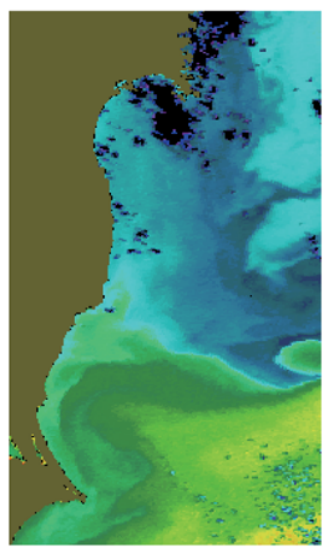

(e) $6 / 6$

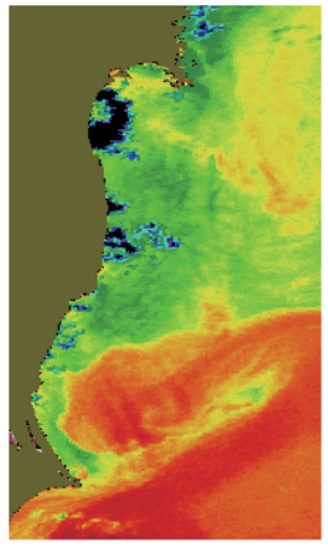

(c) $4 / 27$

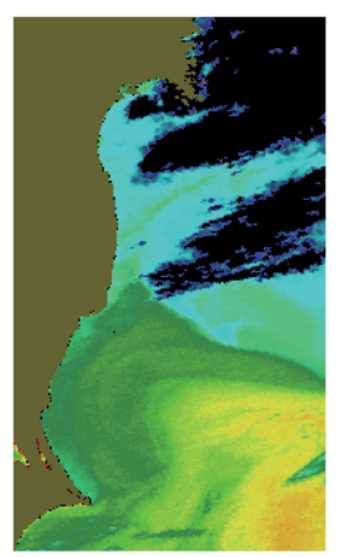

(f) $6 / 29$

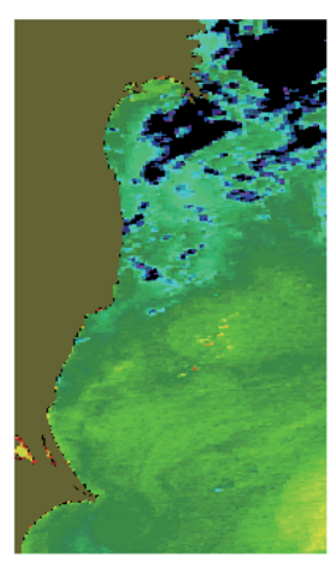

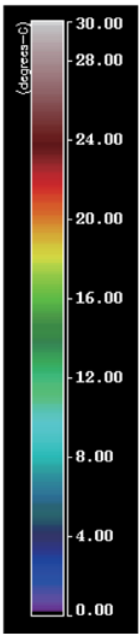

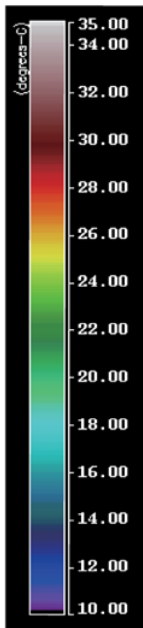

Fig. 5. The SST observed by MODIS from March to June 2011. Dark regions are where clouds exist. Color contours are shown on the top right for (a-e) but bottom right for (f).

The spatial distribution of radionuclides in bottom sediment phase shows high values near the source with a meridional asymmetry, similar to those in dissolved phase and LPM phase; more radionuclides are located in the Sendai Bay than along the coast of Ibaraki (Fig. 7a-d). An increase of radionuclides in bottom sediment phase is found along the coast of Ibaraki at the end of May, when a strong southward flow advects the radionuclides from the north (Fig. 7e). However, the duration of this southward flow is only for a few days. The time necessary for adsorption to bottom sediments to occur is small and so the increase of radionuclides in bottom sediment phase is also limited compared to the Sendai Bay (Fig. 7f).

Although the number of observation points is limited, the magnitude and the spatial distribution of radionuclides in seawater (Fig. 6g-i) and bottom sediments (Fig. 7g-i) agree reasonably well with those observed. Enhanced dis- persion of radionuclides in dissolved and LPM phases occur towards the open ocean in June (Fig. 6c-f). This behavior also matches well with the general increase in the concentration values found in observations offshore (Fig. $6 \mathrm{~h}$ and i). The concentration of radionuclides in dissolved phase near the Kuroshio Extension region is also of similar magnitude to those observed (Buesseler et al., 2012). Higher concentration values found in both seawater and bottom sediments are generally located to the north of the FNPP but an increase in concentration is also observed to the south of FNPP from May to June (Fig. 7h and i). Such increase is in accordance with the southward advection of radionuclides that is simulated along the Ibaraki coast at the end of May because of an extra-tropical cyclone (Figs. 6e and 7e). High concentration values observed about $30 \mathrm{~km}$ offshore of the FNPP in seawater during April (Figs. $6 \mathrm{~g}$ and $7 \mathrm{~g}$ ) is not simulated in our model. However, as past studies have shown (e.g. Tsumune 

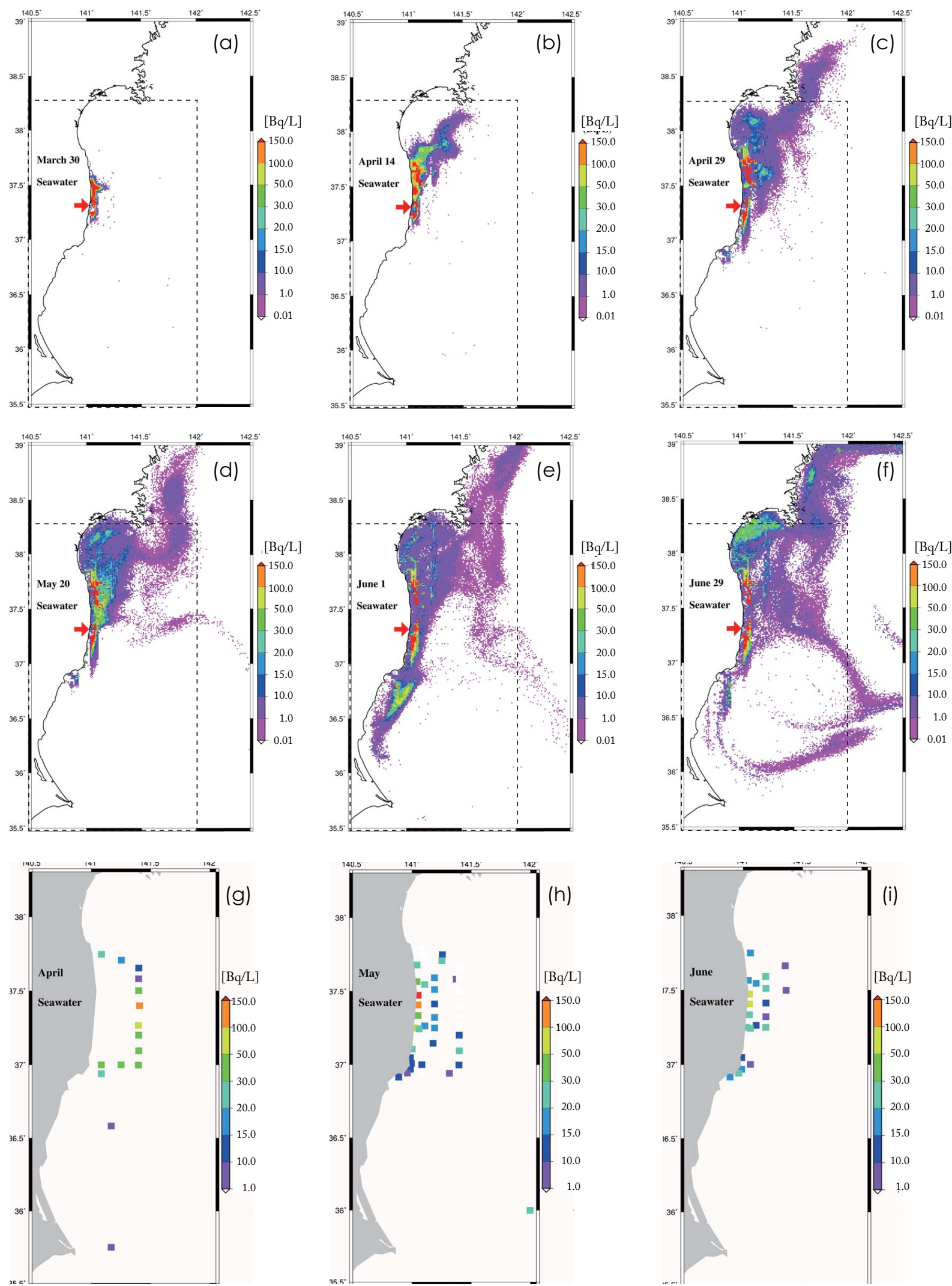

Fig. 6. (a-f) Radionuclide concentrations in seawater (dissolved and LPM phases) collected between 0-150 m in CTRL: (a) 30 March, (b) 14 April, (c) 29 April, (d) 20 May, (e) 1 June, and (f) 29 June 2011. (g-i) Monthly averages of observed radionuclide concentration in seawater: (g) April, (h) May, and (i) June 2011. 

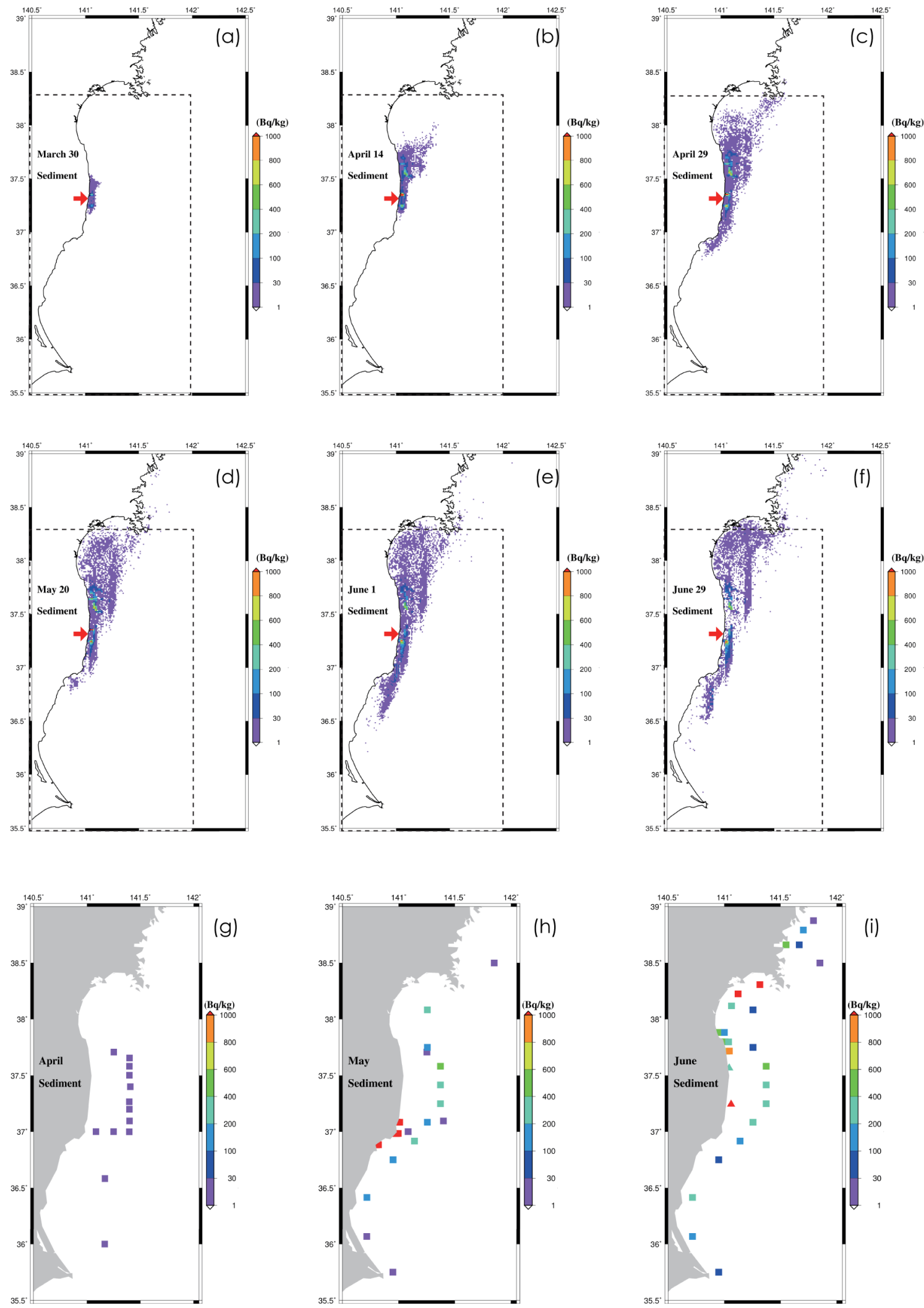

Fig. 7. (a-f) Radionuclide concentration in bottom sediment phase in CTRL [Bq kg ${ }^{-1}$ dry]: (a) 30 March, (b) 14 April, (c) 29 April, (d) 20 May, (e) 1 June, and (f) 29 June 2011. (g-i) Monthly averages of observed radionuclide concentration in bottom sediments: (g) April, (h) May and (i) June 2011. Note that data from TEPCO are measured in $\left[\mathrm{Bq} \mathrm{kg}{ }^{-1}\right.$ wet] and are shown in triangles. The values are also converted to $\left[\mathrm{Bq} \mathrm{kg}^{-1} \mathrm{dry}\right]$ by multiplying the value by 0.75 (MEXT, 2011). 

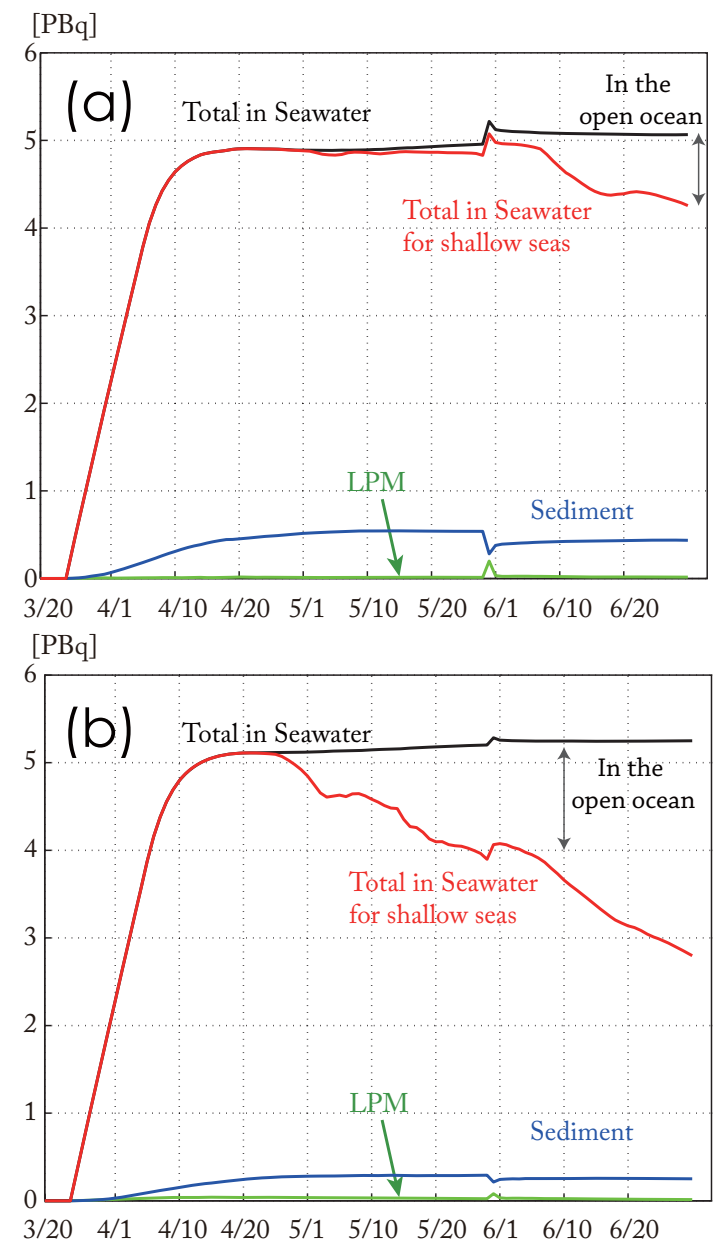

Fig. 8. (a) Time series of radionuclides in CTRL. (b) Time series of radionuclides in SMIX. Green and blue lines show the radionuclides in LPM phase and bottom sediment phase, respectively. Black solid line is the sum of radionuclides in dissolved and LPM phases including those that exited from the model domain. Red line is the sum of radionuclides in dissolved and LPM phases that are located in shallow seas $(<200 \mathrm{~m})$. The difference between the black and red lines is the number of radionuclides in the open ocean $(>200 \mathrm{~m})$.

et al., 2012), these high values are not only due to oceanic processes but also due to atmospheric deposits.

\subsubsection{Time dependence}

The time series showing the number of radionuclides in each phase show radionuclides in bottom sediment phase increasing soon after the radionuclides are introduced on 26 March (Fig. 8a). The accumulation in bottom sediment phase begins in a few days, which matches well with the timescale of radionuclides in seawater reaching the bottom where it is only a few tens of meters deep through vertical mixing. As mentioned earlier, when the vertical mixing coefficient is on the order of $10^{-2} \mathrm{~m}^{2} \mathrm{~s}^{-1}$, the timescale is only a few days for a $50 \mathrm{~m}$-deep ocean. While the transfer rate from dissolved to
LPM phase is slow, significantly large initial concentration near the source as well as the strong vertical mixing near the coast enables the radionuclides to migrate to LPM phase and then settle as bottom sediment phase.

By late April, a month after the major release of the radionuclides, most of the migration to bottom sediments has taken place and about $0.43 \mathrm{PBq}$ are found in bottom sediment phase near the coast. Accumulation in bottom sediment phase is observed in the shallow regions $(<50 \mathrm{~m})$ in May but desorption from bottom sediment to dissolved phase also occur and limits their further increase. A strong but short erosion event is also simulated at the end of May when a strong southward flow is induced by the extra-tropical cyclone. A rapid transfer of radionuclides from bottom sediment phase to dissolved and LPM phases occur during this event. However, these radionuclides rapidly return to bottom sediments. Dispersion of radionuclides towards the open ocean begins from May and by late June, about $1 \mathrm{PBq}$ of radionuclides are found in the open ocean $(>200 \mathrm{~m})$. Those in bottom sediment phase remain along the coast and only a slight decrease is found from May-June.

The majority of the accumulation of radionuclides to bottom sediments and their spatial distribution along the coast appear to be decided during the first 30-40 days or so. This suggests that the oceanic flow field during the first month has a profound impact on the amount and the spatial distribution of radionuclides in bottom sediment phase that will affect the coast for a much longer timescale. For the radionuclides released from the FNPP, the northward flow and the northerly wind during March to April are likely responsible for creating the meridional asymmetry in the distribution of radionuclides and preventing radionuclides from being advected eastward to the open ocean (Figs. 6 and 7). When the offshore motion is weak during the first month, radionuclides remain in the shallow seas. Such conditions will enhance their accumulation to bottom sediments. Once the radionuclides are accumulated in bottom sediment phase, they are likely to remain along the coast for some time and then delay their dispersion to the open ocean significantly. If the offshore motion is much stronger during the first month, the radionuclides will be advected to a deep region. Then the accumulation to bottom sediments is likely to be much limited and their dispersion to the open ocean is likely to accelerate.

\section{The impact of vertical mixing}

CTRL showed a significant amount of radionuclides remaining in the bottom sediments along the coast of Fukushima even after few months after their release. We will next examine how these modeling results are sensitive to vertical mixing by comparing CTRL with SMIX. 

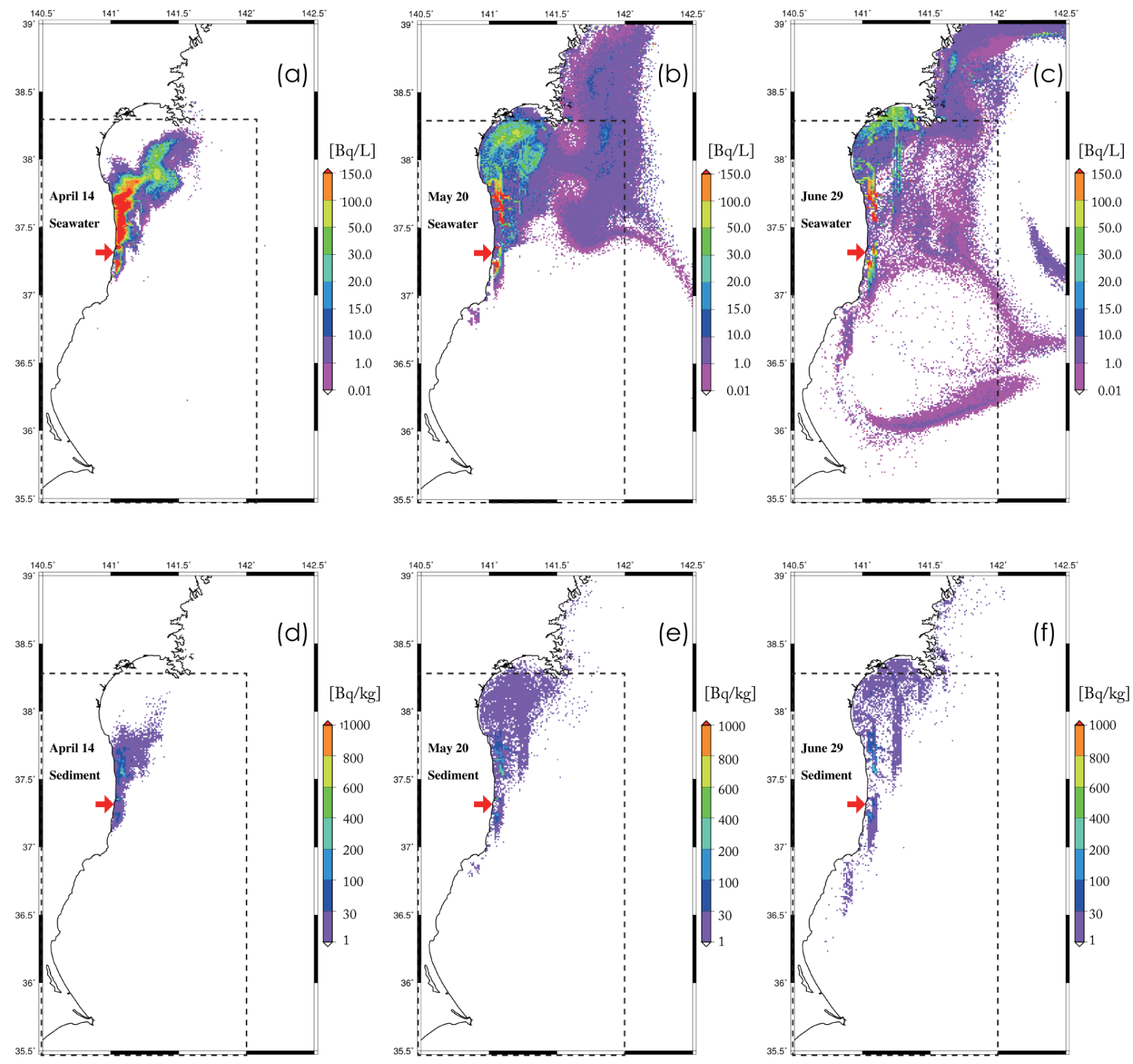

Fig. 9. Model results of SMIX. Depth-averaged radionuclide concentration in seawater phase (dissolved and LPM phases): (a) 14 April, (b) 20 May, (c) 29 June 2011. (d-f) Radionuclide concentration in bottom sediment phase: (d) 14 April, (e) 20 May, (f) 29 June 2011.

\subsection{The spatial structure of the dispersion}

We find the basic spatial pattern of the dispersion in SMIX (Fig. 9a-f) similar to CTRL (Fig. 6a-f and Fig. 7a-f). Northward advection occurs in April and offshore dispersion strengthens in May and June. This is because the dispersion of radionuclides for dissolved and LPM phases are determined mostly by the oceanic flow and the wind, which is the same for CTRL and SMIX. The distribution of the radionuclides in bottom sediment phase depends on those in dissolved and LPM phases in the shallow regions so SMIX also shows similar behavior. However, more radionuclides in dissolved and LPM phases are found in the open ocean and they are more widely spread than in CTRL (Figs. 6e and 9b). For those in bottom sediment phase, the differences are quite complex. The values found near the FNPP show dramatic decrease from CTRL to SMIX, while offshore values are slightly enhanced; concentrations found in Sendai Bay in May-June are higher in SMIX than in CTRL. Such differences arise because the radionuclides take longer to reach the bottom when vertical mixing is small. The radionuclides are then capable of being advected further away from the source before they reach the bottom, making transfer to bottom sediment phase limited near the source but enhanced further away. 


\subsection{Time dependence}

The time series showing the number of radionuclides in each phase shows those in bottom sediment phase increasing around mid-April in SMIX (Fig. 8b), which is about a week later than CTRL (Fig. 8a). The accumulation speed is about half and the total number of radionuclides in bottom sediments is also half, $0.24 \mathrm{PBq}$. When the magnitude of vertical mixing is small, it takes longer time for the radionuclides to reach the bottom. So the oceanic flow field is capable of advecting more radionuclides offshore, where the topography is much deeper. Because it requires more time for radionuclides to transfer to bottom sediment phase where the topography is deep, the amount of deposition further decreases.

Not only do more radionuclides remain in dissolved phase in SMIX compared to CTRL, but the dispersion to the open ocean is also accelerated. The amount of radionuclides in seawater that have escaped to the open ocean (where the bathymetry is deeper than $200 \mathrm{~m}$ ) is about $2.8 \mathrm{PBq}$ by June. This is more than twice as much as that found in CTRL. Such rapid dispersion occurs when vertical mixing is small because there is less transfer to bottom sediment phase and more radionuclides remain near the surface, where the flow is much faster. More radionuclides are then capable of being advected offshore. A decrease in vertical mixing therefore reduces the number of radionuclides that are adsorbed in bottom sediments near the coast and accelerates the number of radionuclides that disperses to the open ocean.

\section{Summary and closing remarks}

In this study, we investigated the impact of phase transfer on the dispersion of radionuclides that were released into the ocean from the FNPP. A Lagrangian particle tracking-ocean circulation coupled model was used with the migration of radionuclides to different phases solved based on the stochastic method of Periàñez (2000), Periàñez and Elliott (2002), and Kobayashi (2007). Three phases of radionuclides were considered; those dissolved in seawater (dissolved phase), those adsorbed in large particulate matter (LPM phase), and those adsorbed in bottom sediments (bottom sediment phase). Many of the past studies have investigated the mechanism responsible for the dispersion of radionuclides from the FNPP using a numerical model but in absence of phase transfer. Here we summarize two major outcomes of our study.

The majority of the adsorption to bottom sediments likely occurred within the first month or two. Since many radionuclides remain trapped in bottom sediments once they are adsorbed, the oceanic flow field during the first month has a profound influence on the spatial distribution of radionuclides near the coast that will continue for some time. For March 2011, a weak northward flow along the shelf break and a westward surface Ekman transport kept many radionuclides to remain near the coast. Such a flow field likely en- hanced the adsorption to bottom sediments and decelerated the rapid dispersion of radionuclides to the open ocean.

Vertical mixing can significantly affect the amount of the radionuclides that transfer to bottom sediment phase. Smaller mixing leads to less accumulation of radionuclides in bottom sediments because it slows the time the radionuclides need to reach the bottom, where deposition occurs. On the other hand, the dispersion of radionuclides to its surroundings and the open ocean will accelerate because more radionuclides remain near the surface.

It is worth noting here at the end that there are obviously limitations to the model results we presented in this paper. First, there should be some differences between the flow fields simulated in our model from reality, although we consider its general features reasonable. We do find the flow field sensitive to the lateral boundary condition, since the region is under the strong influence of the Kuroshio, one of the most energetic currents in the world. For example, the southward flow along the coast of Ibaraki that is simulated during the last few days of May in our model could be stronger and longer. Such a flow field will enable more radionuclides to intrude to the southern coast of Ibaraki, enter the Kuroshio Extension, and disperse to the open ocean. Observations show some Fukushima-origin radionuclides in bottom sediments near the southern tip of Ibaraki and suggest the occurrence of such flow. Second, the amount of radionuclides that are adsorbed to bottom sediments are somewhat sensitive to the parameters used in the particle-tracking model. The qualitative behaviors of the radionuclides shown in this study will likely to hold to its first order. For further realistic modeling, however, the model needs to incorporate temporal and spatial varying concentration for LPM, multiple classes for particulate matters, or two-step transfer models for bottom sediments. Third, we have neglected the impact of freshwater inputs from local rivers, which could limit the magnitude of vertical mixing through enhanced stratification. Inclusion of rivers may make the dispersion of radionuclides along the coast of Fukushima resemble SMIX more than CTRL. Further investigation on the impact of these features mentioned above on the behavior of radionuclides is beyond the scope of this study. Nonetheless, our study suggests the need to use models that incorporate the migration of radionuclides into different phases for more detailed understandings of their dispersion from the FNPP near the coast. 
Acknowledgements. The authors thank M. Toratani for the satellite images from MODIS data used in Fig. 5, Miyazawa for JCOPE2 data outputs, and the numerical modeling subgroup of the Oceanographic Society of Japan leaded by M. Ikeda for many discussions and inputs. Comments by anonymous reviewers greatly helped improve the paper, and we also thank T. Kobayashi, K.-S. Suh, and B.-I. Min for discussions in developing the radionuclide dispersion model.

Edited by: H. Nies

\section{References}

Amante, C. and Eakins, B. W.: ETOPO1 1 Arc-Minute Global Relief Model: Procedures, Data Sources and Analysis. NOAA Technical Memorandum NESDIS NGDC-24, 19 pp., March 2009.

Bailly du Bois, P., Laguionie, P., Boust, D., Korsakissok, I., Didier, D., and Fiévet, B.: Estimation of marine source-term following Fukushima Dai-ichi accident, J. Environ. Radioact., 114, 2-9, doi:10.1016/j.jenvrad.2011.11.015, 2012.

Buesseler, K., Jayne, S. R., Fisher, N. S., Rypina, I. I., Baumann, H., Baumann, Z., Breier, C. F., Douglass, E. M., George, J., Macdonald, A. M., Miyamoto, H., Nishikawa, J., Pike, S. M., and Yoshida, S.: Fukushima-derived radionuclides in the ocean and biota off Japan, Proc. Natl. Acad. Sci. USA, 109, 5984-5988, doi:10.1073/pnas.1120794109, 2012.

Choi, Y. J., Abe, A., and Takahashi, K.: Development of OilSpill Simulation System based on the Global Ocean-Atmosphere Model, Gas Transfer at Water Surface, 6, 407-418, 2011.

Choi, Y., Takahashi, K., Abe, A., Nishio, S., and Sou, A.: Simulation of Deepwater Horizon Oil spill using Coupled AtmosphereOcean Model, J. Japan Inst. Mar. Engin., 48, 105-109, 2012.

Estournel, C., Bosc, E., Bocquet, M., Ulses, C., Marsaleix, P., Winiarek, V., Osvath, I., Nguyen, C., Duhaut, T., Lyard, F., Michaud, H., and Auclair, F.: Assessment of the amount of cesium-137 released into the Pacific Ocean after the Fukushima accident and analysis of its dispersion in Japanese coastal waters, J. Geophys. Res., 117, C11014, doi:10.1029/2012JC007933, 2012.

Honda, M. C., Aono, T., Aoyama, M., Hamajima, Y., Kawakami, H., Kitamura, M., Masumoto, Y., Miyazawa, Y., Takigawa, M., and Saino, T.: Dispersion of artificial caesium-134 and -137 in the western North Pacific one month after the Fukushima accident. Geochem. J., 46, e1-e9, 2012.

Kawamura, H., Kobayashi, T., Furuno, A., In, T., Ishikawa, Y., Nakayama, T., Shima, S., and Awaji, T.: Preliminary numerical experiments on oceanic dispersion of 131I and 137Cs discharged into the ocean because of the Fukushima Daiichi nuclear power plant disaster, J. Nucl. Sci. Technol., 48, 1349-1356, doi:10.1080/18811248.2011.9711826, 2011.

Kida, S.: The Impact of Open Oceanic Processes on the Antarctic Bottom Water Outflows, J. Phys. Oceanogr., 41, 1941-1957, doi:10.1175/2011JPO4571.1, 2011.

Kobayashi, T., Otosaka, S., Togawa, O., and Hayashi, K.: Development of a Non-conservative Radionuclides Dispersion Model in the Ocean and its Application to Surface Cesium-137 Dispersion in the Irish Sea, J. Nuclear Sci. Tech., 44, 238-247, 2007.
Lafite, R., Shimwell, S., Grochowski, N., Dupont, J.-P., Nash, L., Salomon, J.-C., Cabioch, L., Collins, M., and Gao, S.: Suspended particulate matter fluxes through the Strait of Dover, English Channel: observations and modeling, Oceanol. Act., 23, 687700, 2000.

Large, W. G. and S. Pond: Open ocean momentum flux measurements in moderate to strong winds, J. Phys. Oceanogr., 11, 324336, 1981.

Masumoto, Y., Miyazawa, Y., Tsumune, D., Tsubono, T., Kobayashi, T., Kawamura, H., Estournel, C., Marsaleix, P., Lanerolle, L., Mehra, A., and Garraffo, Z. D.: Oceanic Dispersion Simulations of ${ }^{137} \mathrm{Cs}$ Released from the Fukushima Daiichi Nuclear Power Plant, Elements, 8, 207-212, doi:10.2113/gselements.8.3.207, 2012.

Mehta, A. J.: On estuarine cohesive sediment suspension behavior, J. Geophys. Res., 94, 14303-14314, 1989.

Ministry of Education, Culture, Sports, Science and Technology (MEXT): Monitoring information of environmental radioactivity level, available at: http://radioactivity.mext.go.jp/en/, 2012.

Miyazawa, Y., Zhang, R., Guo, X., Tamura, H., Ambe, D., Lee, J.S., Okuno, A., Yoshinari, H., Setou, T., and Komatsu, K.: Water mass variability in the western North Pacific detected in a 15year eddy resolving ocean reanalysis, J. Oceanogr., 65, 737-756, doi:10.1007/s10872-009-0063-3, 2009.

Miyazawa, Y., Masumoto, Y., Varlamov, S. M., and Miyama, T.: Transport simulation of the radionuclide from the shelf to open ocean around Fukushima, Continental Shelf Res., 50/51, 16-29, 2012.

Miyazawa, Y., Masumoto, Y., Varlamov, S. M., Miyama, T., Takigawa, M., Honda, M., and Saino, T.: Inverse estimation of source parameters of oceanic radioactivity dispersion models associated with the Fukushima accident, Biogeosciences, 10, 2349-2363, doi:10.5194/bg-10-2349-2013, 2013.

Noh, Y. and Jin Kim, H.: Simulations of temperature and turbulence structure of the oceanic boundary layer with the improved near-surface process, J. Geophys. Res., 104, 1562115634, doi:10.1029/1999JC900068, 1999.

Nicholson, J. and O'Connor, B.: Cohesive Sediment Transport Model, J. Hydraulic Engineering, 112, 621-640, 1986.

Nuclear Emergency Response Headquarters (NERH), Government of Japan: Report of the Japanese Government to the IAEA Ministerial Conference in Nuclear Safety - The accident at TEPCO's Fukushima Nuclear Power Stations, 2011.

Periànez, R.: Modelling the tidal dispersion of ${ }^{137} \mathrm{Cs}$ and ${ }^{239,240} \mathrm{Pu}$ in the English Channel, J. Environ. Radioactivity, 49, 259-277, 2000.

Periàñez, R. and Elliott, A. J.: A particle-tracking method for simulating the dispersion of non-conservative radionuclides in coastal waters, J. Environ. Radioactivity, 58, 13-33, 2002.

Periàñez, R., Suh, K., and Min, B.: Local scale marine modeling of Fukushima releases. Assessment of water and sediment contamination and sensitigvity to water circulation description, Mar. Pollut. Bull, 64, 2333-2339, 2012.

Sternberg, R. W., Berhane, I., and Ogston, A. S.: Measurement of size and settling velocity of suspended aggregates on the northern California continental shelf, Mar. Geol. 154, 43-53, 1999.

Tokyo Electric Power Corporation (TEPCO): Detection of radioactive materials from the seawater around the discharge canal of Fukushima Daiichi Nuclear Power Station, Press Release, avail- 
able at: http://www.tepco.co.jp/en/nu/fukushima-np/f1/index2-e. html, 2011.

Tsumune, D., Tsubono, T., Aoyama, M., and Hirose, K.: Distribution of oceanic ${ }^{137} \mathrm{Cs}$ from the Fukushima Dai-ichi Nuclear Power Plant simulated numerically by a regional ocean model, J. Environ. Radioactivity, 111, 100-108, 2012.

Van Alphen, J. S. L. J.: A mud balance for Belgian-Dutch coastal waters between 1969 and 1986, Neth. J. Sea Res. 25, 19-30, 1990.
Van Raaphorst, W., Philippart, C. J. M., Smit, J. P. C., Dijkstra, F. J., and Malschaert, J. F. P.: Distribution of suspended particulate matter in the North Sea as inferred from NOAA/AVHRR reflectance images and in situ observations, J. Sea Res. 39, 197215, 1998.

Yasuda, I.: Hydrographic Structure and Variability in the Kuroshio-Oyashio Transition Area, J. Oceanogr., 59, 389-402, doi:10.1023/A:1025580313836, 2003. 